\title{
Low-grade astrocytoma - surgical outcomes in eloquent versus non-eloquent brain areas
}

Astrocitoma de baixo grau - resultado cirúrgico em área eloquente versus não eloquente

André de Macedo Bianco', Flavio Key Miura², Carlos Clara ${ }^{3}$, Jose Reynaldo W. Almeida , Clemar Correa da

Silva², Manoel Jacobsen Teixeira², Suely K. Nagahashi Marie²

\begin{abstract}
A retrospective study of 81 patients with low-grade astrocytoma (LGA) comparing the efficacy of aggressive versus less aggressive surgery in eloquent and non-eloquent brain areas was conducted. Extent of surgical resection was analyzed to assess overall survival (OS) and progression-free survival (PFS). Degree of tumor resection was classified as gross total resection (GTR), subtotal resection (STR) or biopsy. GTR, STR and biopsy in patients with tumors in non-eloquent areas were performed in 31, 48 and 21\% subjects, whereas in patients with tumors in eloquent areas resections were 22.5, 35 and 42.5\%. Overall survival was 4.7 and 1.9 years in patients with tumors in non-eloquent brain areas submitted to GTR/STR and biopsy $(\mathrm{p}=0.013)$, whereas overall survival among patients with tumors in eloquent area was 4.5 and 2.1 years $(p=0.33)$. Improved outcome for adult patients with LGA is predicted by more aggressive surgery in both eloquent and non-eloquent brain areas.
\end{abstract}

Key words: astrocytoma, survival analysis, neurosurgery.

\section{RESUMO}

Foi realizado estudo retrospectivo em 81 pacientes com astrocitoma de baixo grau (LGA) comparando a eficácia da ressecção cirúrgica com cirurgia menos agressiva em relação à área eloquente e não eloquente do cérebro. A extensão da ressecção cirúrgica foi analisada para avaliar a sobrevida geral (OS) e o tempo livre de doença (PFS). O grau da ressecção cirúrgica foi classificado como ressecção total (GTR), subtotal (STR) e biópsia. Nos pacientes com lesão em área não eloquente foram realizadas GTR, STR e biópsia em 31, 48 e 21\% dos casos, enquanto, naqueles com lesão em área eloquente, em 22,5, 35 e 42,5\%, respectivamente. A sobrevida geral foi de 4,7 e 1,9 anos em pacientes com lesões em área não eloquente submetidos à GTR/STR e biópsia ( $p=0,013)$. Nos pacientes com lesão em áreas eloquentes, a sobrevida geral foi de 4,5 e 2,1 anos ( $p=0,33)$, respectivamente. A extensão da ressecção é fator preditivo de sobrevida tanto nas lesões em áreas eloquentes quanto nas não eloquentes.

Palavras-Chave: astrocitoma, análise de sobrevida, neurocirurgia.

Primary central nervous system (CNS) tumors comprise a heterogeneous group of benign and malignant neoplasms. The most common tumors are collectively referred to as gliomas. These tumors are classified according to cell origin and graded based on standard histopathological features defined by the World Health Organization (WHO) - Classification of Tumors of the Central Nervous System (latest 2007 edition) $)^{1,2}$.

Diffuse low-grade gliomas (LGGs), designated as WHO grade II classification, encompass glial tumors that are infiltrative in nature with low proliferative activity, including astrocytomas, oligodendrogliomas and mixed oligoastrocytomas.

An estimated 2,000 to 3,000 LGGs are diagnosed in the United States every year, accounting for nearly $15 \%$ of all primary brain tumors. These cases are predominantly astrocytomas. Peak incidence occurs in individuals between 35 and 44 years of age ${ }^{3}$. The median survival of patients with LGG is between five and ten years ${ }^{4-11}$. Despite this long survival time, $50-75 \%$ of these patients die as a result of either tumor recurrence or malignant progression ${ }^{6,11}$.

Whereas expectant management was once acceptable, current trends and mounting evidence now favor more active management, including extensive surgical resection ${ }^{12-15}$. Nevertheless, studies tend to compare survival in good surgical candidates (especially those with tumors in non-eloquent brain areas) with survival in poor surgical candidates (with diffuse infiltrating tumors in eloquent brain areas) ${ }^{7}$.

${ }^{1}$ Post-graduate student, Department of Neurology, Universidade de São Paulo (USP) Medical School, São Paulo SP, Brazil;

${ }^{2}$ Department of Neurology, Hospital das Clínicas, USP Medical School, São Paulo SP, Brazil;

${ }^{3}$ Department of Neurology and Neurosurgery, Hospital de Câncer de Barretos, Barretos SP Brazil.

Correspondence: André de Macedo Bianco; Rua Peixoto Gomide 515 / conj. 84; 01409-001 São Paulo SP - Brasil; E-mail: ambbr@uol.com.br

Conflict of interest: There is no conflict of interest to declare.

Received 19 December 2012; Received in final form 23 August 2012; Accepted 30 August 2012 
We performed a retrospective study in a homogeneous series of LGG, consisting of adult pure diffuse astrocytoma (WHO grade II), comparing the efficacy of aggressive versus less aggressive surgery in patients with tumors in eloquent and non-eloquent brain areas.

\section{METHODS}

Adult patients who underwent initial surgery at Hospital das Clínicas de São Paulo and Hospital de Câncer de Barretos Pio XII for hemispheric low-grade astrocytoma (LGA) between 1999 and 2008 were selected. The histopathological diagnosis of LGA was based on WHO guidelines, and the revision was performed by one neuropathologist for all cases included from both institutions. Oligodendroglioma and mixed glioma were excluded, as were two cases of gliomatosis cerebri.

Clinical data including age and sex, initial symptoms, tumor location, extent of surgical resection, adjuvant therapy, date of last follow-up or contact, date of death, time interval for disease progression and overall survival time were analyzed to assess outcome measures: overall survival (OS) and progressionfree survival (PFS). Overall survival was defined as the time from surgery to death and progression-free survival as time from surgery to demonstration of unequivocal increase in tumor size or demonstration of gadolinium enhancement on follow-up imaging and/or higher-grade tumor on subsequent surgery or biopsy ${ }^{12}$. Patients with no known progression/malignant progression were censored as of their last scan date.

Based on the data collected, patients were organized into two groups: tumor in non-eloquent brain area and tumor in eloquent brain area when lesion involved one or more of the following: internal capsule, insula, basal ganglia, language cortex, sensory motor cortex, thalamus and hypothalamus.

Outpatients were followed-up every three months. Semianually sequential follow-up neuroimages were compared by neurosurgeons, excluding the surgeon who carried out the operation, to determine the presence of residual lesion and recurrence or malignant progression of the tumor. The degree of tumor resection was classified as: (1) gross total resection (GTR) when complete resection of the lesion was achieved based on Fluid Attenuated Inversion Recovery (FLAIR) signal abnormality on magnetic resonance imaging (MRI); (2) subtotal resection (STR) when residual FLAIR signal abnormality was detected on postoperative images; and (3) biopsy for either open or stereotactic procedures.

Postoperative limited-radioterapy, with or without adjuvant chemotherapy, was delivered to the patients with progression/malignization and those with high risk (over 40 years, tumor crossing midline, partial resection). Total dose was 54 Gy with fractions of 2 Gy each. Adjuvant drugs were lomustine or temozolomide.

The survival curves were constructed using the KaplanMeier method and differences were evaluated using the
Log-rank test. The other parameters were analyzed by multivariate analysis using Cox proportional hazards. Statistical tests were performed using the R platform, version 2.8.0 (Copyright (C) 2008 The R Foundation for Statistical Computing) and SPSS 15.0 software (SPSS, Chicago, IL, USA), with $\mathrm{p}<0.05$ being considered statistically significant.

The ethics committees for human research of both institutions approved this study.

\section{RESULTS}

Among the 82 patients who met the inclusion criteria, 47 (57\%) were male, and patient age ranged from 18 to 69 years old (median of 37 yo). Epilepsy was the most frequent symptom, followed by headache and cognitive and motor changes.

Nineteen $(23 \%)$ patients were followed-up for less than two years, $22(27 \%)$ patients were followed-up for a period between 3 and 4 years, 31 (38\%) patients were followed-up for a period between 4 and 8 years and 10 (12\%) patients were followed-up for more than 8 years (median of 4.8 years). Thirtyfour $(41 \%)$ patients died during the follow-up period. Tumor progression and/or malignant degeneration were detected in $47(57 \%)$ patients with a median time of 2 years. Of this group, 14 patients (30\%) were still alive. LGAs primarily occurred in non-eloquent areas in $42(51 \%)$ cases while in eloquent areas in 40 (49\%) cases (Table).

\begin{tabular}{|c|c|c|}
\hline Characteristics & Non-eloquent & Eloquent* \\
\hline $\begin{array}{l}\text { Age at diagnosis } \\
18-30 \\
31-40 \\
41-50 \\
>51 \\
\text { Median }\end{array}$ & $\begin{array}{r}14 \\
12 \\
10 \\
6 \\
37\end{array}$ & $\begin{array}{r}13 \\
13 \\
8 \\
6 \\
37\end{array}$ \\
\hline $\begin{array}{l}\text { Sex } \\
\text { Male } \\
\text { Female }\end{array}$ & $\begin{array}{l}27 \\
15\end{array}$ & $\begin{array}{l}20 \\
20\end{array}$ \\
\hline $\begin{array}{l}\text { KPS at diagnosis } \\
100-90 \% \\
80-70 \% \\
60-50 \%\end{array}$ & $\begin{array}{r}28 \\
9 \\
5\end{array}$ & $\begin{array}{r}30 \\
7 \\
3\end{array}$ \\
\hline $\begin{array}{l}\text { Extent of resecti } \\
\text { GTR } \\
\text { STR } \\
\text { Biopsy }\end{array}$ & $\begin{array}{r}13 \\
20 \\
9\end{array}$ & $\begin{array}{r}9 \\
14 \\
17\end{array}$ \\
\hline $\begin{array}{l}\text { Post-operative a } \\
\text { Radiotherapy } \\
\text { Yes } \\
\text { No }\end{array}$ & $\begin{array}{l}30 \\
10\end{array}$ & $\begin{array}{l}31 \\
11\end{array}$ \\
\hline $\begin{array}{l}\text { Chemotherapy } \\
\text { Yes } \\
\text { No }\end{array}$ & $\begin{array}{r}4 \\
38\end{array}$ & $\begin{array}{r}8 \\
32\end{array}$ \\
\hline
\end{tabular}

KPS: Karnofsky Performance Scale; GTR: gross total resection; STR: subtotal resection.

*Tumor involved one or more of the following: internal capsule, insula, basal ganglia, language cortex, sensory motor cortex, thalamus and hypothalamus. 
A total of $58(70 \%)$ patients had a Karnofsky score (KPS) of 100/90 at diagnosis, while 24 (30\%) patients had a KPS $£ 80$.

Multivariate cox regression assessments (KPS, age, sex, tumor location) revealed that KPS at diagnosis was an independent predictive factor of both OS (hazard ratio $=0.31 ; 95 \% \mathrm{CI}$ 0.135-0.71; $\mathrm{p}=0.006$ ) and PFS (hazard ratio $=0.167 ; 95 \%$ CI $0.057-0.492 ; \mathrm{p}=0.001$ ).

GTR, STR and biopsy in patients with tumors in non-eloquent areas were performed in $13(31 \%), 20(48 \%)$ and $9(21 \%)$ subjects respectively, while for patients with tumors in eloquent areas resections were 9 (22.5\%), 14 (35\%) and 17 (42.5\%), respectively.

Overall survival time was 4.7 and 1.9 years in patients with tumors in non-eloquent brain areas that had GTR/STR and biopsy, respectively ( $\mathrm{p}=0.013)$. For patients with tumors in eloquent areas undergoing GTR/STR and biopsy, OS was 4.5 and 2.1 years, respectively ( $\mathrm{p}=0.33$ ). (Figs. 1 and 2)

A permanent new neurological deficit determined by the surgical procedure occurred in four (5\%) cases and surgical infection occurred in two cases (2\%). There was no operative mortality.

\section{DISCUSSION}

Safety concerns over treatment for patients with low-grade gliomas have not yet been sufficiently resolved to reach a consensus opinion and rational standard of care. Extent of surgical resection, timing for adjuvant radiotherapy and indication of chemotherapy for hemispheric LGG are aspects of clinical management, which remain controversial. Small study size, heterogeneity of inclusion criteria, distinct demographic series and different histological types of tumor were some of the confounding parameters preventing a consensus on the optimal therapeutic approach in this patient group $p^{4,13,16}$.

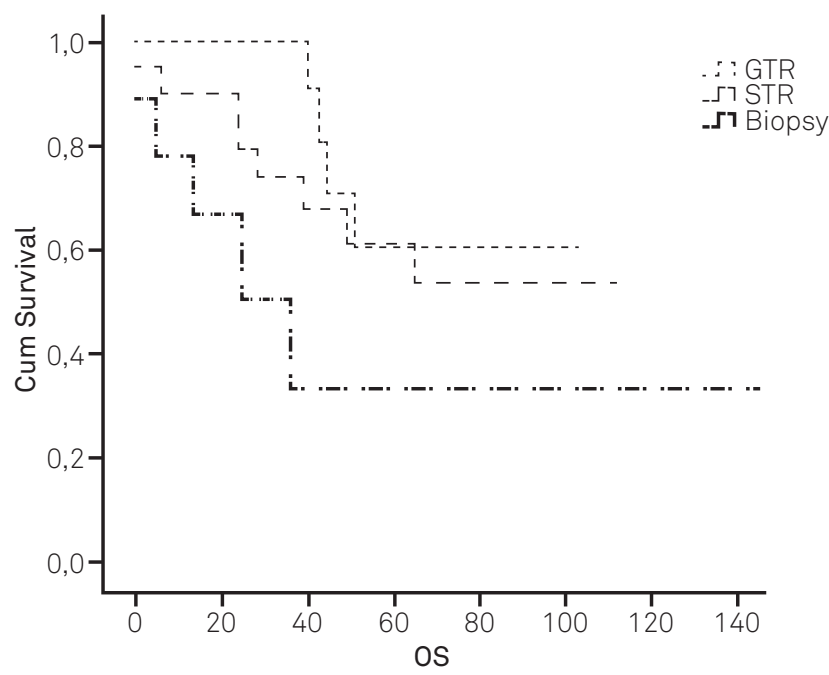

OS: overall survival; GTR: gross total resection; STR: subtotal resection.

Fig 1. Kaplan Mayer - extent of resection and overall survival (months) of patients with tumors in non-eloquent brain area.
A retrospective review of 216 patients with hemispheric LGG, including volumetric analysis of the extent of surgical resection, has shown that patients with at least 90\% resection had 5- and 8-year OS of 97 and 91\%, respectively, whereas patients with less than $90 \%$ resection had 5- and 8-year OS rates of 76 and $60 \%$, respectively ${ }^{12}$.

Chang et al. ${ }^{17}$ proposed a preoperative score system to prognosticate long-term outcomes in patients with LGGs that was validated in a subsequent multi-institutional study ${ }^{18}$. This newer scoring system is unique in that it is the first system to consider eloquence as a poor independent prognostic factor.

We share the view of Kelly ${ }^{7}$ that surgeons tend to opt for more extensive resection of compact tumors, especially those in non-eloquent brain areas, while subjecting diffuse infiltrating tumors in eloquent brain areas to biopsy only. In spite of this evidence, some patients with tumors in non-eloquent area (generally asymptomatic) are indicated for biopsy as primary therapy.

In the present study, we focused the analysis on astrocytoma among the LGGs, excluding pilocytic astrocytomas (WHO Grade I), oligodendroglioma and gliomas with mixed histology. Our results showed that higher KPS at diagnosis and GTR/STR were positive predictive factors for overall survival.

Patients with tumors in non-eloquent brain areas undergoing biopsy have shorter overall survival time than those submitted to GTR/STR. Similarly, patients with tumors in eloquent areas undergoing biopsy have shorter survival than those submitted to GTR/STR although this difference did not reach statistical significance.

Although our results for patients with tumors in eloquent areas were not statistically significant, there is cumulative evidence that GTR at initial diagnosis represents a positive prognostic factor, even in cases with incomplete tumor

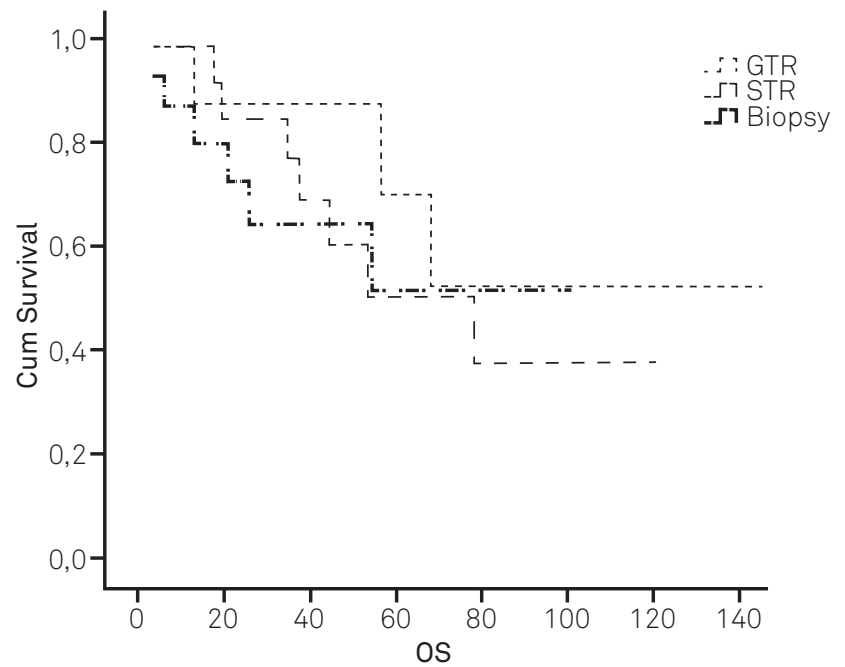

OS: overall survival; GTR: gross total resection; STR: subtotal resection.

Fig 2. Kaplan Mayer - extent of resection and overall survival (months) of patients with tumors in eloquent brain area. 
removal, as patients with more extensive tumor resection had significantly longer OS ${ }^{11,14-16,19,20}$.

Our data showed a very similar KPS at diagnosis between these two groups. Although volumetric analysis of preoperative lesions was not performed systematically in the present series, larger lesions were associated with lower KPS at diagnosis which proved to be an independent predictive factor of OS.

We believe that our OS is lower than that described in the literature because most of studies include others LGG (oligodendroglioma/oligoastrocytoma) and probably because part of our sample has less than 48 months of follow-up.

Patients were submitted to more extensive resections when they presented compact and localized lesions in noneloquent areas while tumors in eloquent area and multilobar in extention were only biopsed. However, when the OS of patients with lesions in non-eloquent and eloquent areas submitted to GTR/STR was compared, no significant difference was observed, confirming that extension of resection impacted positively on survival time. Nevertheless, resection of eloquent area implies higher risk of neurologic deficits, and, therefore, quality of life in medium and long term of those patients should be evaluated for the final decision about these patients management. Moreover, recent intrasurgical devices to monitor the functional behavior of eloquent areas may allow maximize the extent of tumor resection with consequent improvement in survival time.

Additionally, the recent disclosure of biological markers for different brain tumor types may further allow refining the decision making on therapeutic handling of these patients ${ }^{21-23}$.

In conclusion, improved outcome in adult patients with LGA is predicted by more aggressive surgery in both eloquent and non-eloquent brain areas.

\section{References}

1. Lang FF, Gilbert MR. Diffusely infiltrative low-grade gliomas in adults. J Clin Oncol 2006;24:1236-1245.

2. Louis DN, Ohgaki H, Wiestler OD, et al. The 2007 WHO classification of tumours of the central nervous system. Acta Neuropathol 2007;114:97-109.

3. Central Brain Tumor Registry of the United States (CBTRUS). CBTRUS Statistical Report: Primary Brain and Central Nervous System Tumors Diagnosed in the United States 1n 2004-2007. Available at: www. cbtrus.org/2011-NCPR-SEER/WEB-0407-Report-3-3-2011.pdf. Accessed Oct 292012.

4. Duffau H. Surgery of low-grade gliomas: towards a 'functional neurooncolgy'. Curr Opin Oncol 2009;21:543-549.

5. Janny P, Cure H, Mohr M, et al. Low grade supratentorial astrocytomas. Management and prognostic factors. Cancer 1994;73:1937-1945.

6. Keles GE, Lamborn KR, Berger MS. Low-grade hemispheric gliomas in adults: a critical review of extent of resection as a factor influencing outcome.J Neurosurg 2001;95:735-745.

7. Kelly PJ. Gliomas: survival, origin and early detection. Surg Neurol Int 2010;1:96.

8. Leighton C, Fischer B, Bauman G, et al. Supratentorial low-grade glioma in adults: an analysis of prognostic factors and timing of radiation. J Clin Oncol 1997;15:1294-1301.

9. Piepmeier J, Baehring JM. Surgical resection for patients with benign primary brain tumours and low grade gliomas. J Neurooncol 2004;69:55-65.

10. Low Grade Glioma Guidelines Team in association with the Guidelines and Outcomes Committee of the AmericanAssociation of Neurological Surgeons. Practice parametes in adults with suspected or know supratentorial nonoptic pathway low-grade glioma. Neurosurg Focus 1998;4:10.

11. Schiff D, Brown PD, Giannini C. Outcome in adult low grade glioma: the impact of prognostic factors and treatment. Neurology 2007;69:1366-1373.

12. McGirth MJ, Chaichana KL, Attenello FJ, et al. Extent of surgical resection is independently associated with survival in patients

with hemispheric infiltrating low-grade gliomas. Neurosurgery 2008;63:700-708

13. McGirth MJ, Chaichana KL, Gathinji M, et al. Independent association of extent of resection with survival in patients with malignant brain astrocytoma. J Neurosurg 2009;110:156-162.

14. Sanai N, Berger MS. Glioma extent of resection and its impact on patient outcome. Neurosurgery 2008;62:753-764

15. Smith JS, Chang EF, Lamborn KR, et al. Role of extent of resection in the long-term outcome of low-grade hemispheric gliomas. J Clin Oncol 2008;26:1338-1345.

16. Pouratian N, Asthagiri A, Jagannathan J, Shaffrey ME, Schiff D. Surgery insight: the role of surgery in the management of low-grade gliomas. Nat Clin Pract Neurol 2007;3:628-639.

17. Chang EF, Smith JS, Chang SM, et al. Preoperative prognostic classification system for hemispheric low-grade gliomas in adults. J Neurosurg 2008;109:817-824.

18. Chang EF, Clark A, Jensen RL, et al. Multiinstitutional validation of the University of California at San Francisco Low-Grade Glioma Prognostic Scoring System. Clinical article. J Neurosurg 2009;111:203-210.

19. Mariani L, Siegenthaler P, Guzman R, et al. The impact of tumour volume and surgery on the outcome of adults with supratentorial WHO grade II astrocytomas and oligoastrocytomas. Acta Neurochir 2004;146:441-448.

20. Schomas DA, Laack NN, Ra RD, et al. Intracranial low-grade gliomas in adults: 30-year experience with long-term follow-up at Mayo Clinic. Neuro Oncol 2009;11:437-445.

21. Bettegowda C, Agrawal N, Jiao Y, et al. Mutations in CIC and FUBP1 contribute to human oligodendroglioma. Science 2011;333:1453-1455.

22. Heaphy CM, de Wilde RF, Jiao Y, et al. Altered telomeres in tumors with ATRX and DAXX mutations. Science 2011;333:425.

23. Parsons DW, Jones S, Zhang X, et al. An integrated genomic analysis of human glioblastoma multiforme. Science 2008;321:1807-1812. 